\title{
Penile cancer: a Brazilian consensus statement for low- and middle-income countries
}

\author{
Andrey Soares ${ }^{1,2,3}$ - Icaro Thiago de Carvalho ${ }^{4,5}$ [ Aluízio Gonçalves da Fonseca ${ }^{6}$. \\ Antonio Machado Alencar Jr. ${ }^{7,8}$. Carlos Heli Bezerra Leite ${ }^{9}$. Diogo Assed Bastos ${ }^{3,10}$. João Paulo Holanda Soares ${ }^{11}$. \\ Katia Ramos Moreira Leite ${ }^{12}$. Mário Ronalsa Brandão Filho ${ }^{13} \cdot$ Ronald Wagner Pereira Coelho ${ }^{3,14}$. \\ Sandro Roberto de A. Cavallero ${ }^{3,15,16}$. Stênio de Cassio Zequi ${ }^{17,18}$. José de Ribamar Rodrigues Calixto ${ }^{19}$
}

Received: 5 May 2020 / Accepted: 29 September 2020 / Published online: 26 October 2020

(c) The Author(s) 2020

\begin{abstract}
Purpose Penile cancer is highly prevalent in low- and middle-income countries, with significant morbidity and mortality rates. The first Brazilian consensus provides support to improve penile cancer patients' outcomes, based on expert's opinion and evidence from medical literature.

Methods Fifty-one Brazilian experts (clinical oncologists, radiation oncologists, urologists, and pathologists) assembled and voted 104 multiple-choice questions, confronted the results with the literature, and ranked the levels of evidence.

Results Healthcare professionals need to deliver more effective communication about the risk factors for penile cancer. Staging and follow-up of patients include physical examination, computed tomography, and magnetic resonance imaging. Close monitoring is crucial, because most recurrences occur in the first $2-5$ years. Lymph-node involvement is the most important predictive factor for survival, and management depends on the location (inguinal or pelvic) and the number of lymph nodes involved. Conservative treatment may be helpful in selected patients without compromising oncological outcomes; however, surgery yields the lowest rate of local recurrence.
\end{abstract}

Conclusion This consensus provides an essential decision-making orientation regarding this challenging disease.

Keywords Penile cancer · HPV cancer-related · Cancer consensus · Urologic malignancy

\section{Introduction}

Penile cancer is rare in developed countries, but the incidence tends to be higher in developing countries such as Africa, Asia, and South America (GLOBOCAN 2019). Brazil registered 5.7 cases per 100,000 persons-year between 1996 and 2006, and has the third highest incidence worldwide of penile cancer (Cardona and García-Perdomo 2017). More than $50 \%$ of penile cancer cases in Brazil occur in the North and Northeastern areas, confirming the relationship between penile cancer and low socioeconomic status (Favorito et al. 2008).

Electronic supplementary material The online version of this article (https://doi.org/10.1007/s00432-020-03417-1) contains supplementary material, which is available to authorized users.

Andrey Soares

dr.andrey@uol.com.br

Extended author information available on the last page of the article
Penile cancer is highly aggressive (Razzaghi et al. 2018; Pham et al. 2017); thus, timely diagnosis and treatment are crucial. Patients' low educational level and limited access to healthcare in low- and middle-income countries delay the diagnosis, resulting in patients receiving care in more advanced stages.

Actions to prevent, to simplify the early diagnosis, and to provide better management of penile cancer targeting the population and the health professionals, as well as high-quality clinical trials, are needed. Therefore, this consensus statement presents recommendations to improve medical care based on experts' opinions and the best available evidence from the medical literature. The main audience for this consensus statement is clinical oncologists, urologists, radiation oncologists, and any other health professional involved in managing this disease. 


\section{Methods}

The first Brazilian Penile Cancer Consensus was held during the III International Symposium of Genitourinary Review on November 29th and 30th, 2019, in São Paulo, SP, Brazil, through an initiative of the Latin American Cooperative Oncology Group-Genitourinary section (LACOG-GU) and the support of the Brazilian Society of Clinical Oncology (SBOC), the Brazilian Society of Urology (SBU), the Brazilian Society of Radiotherapy (SBRT), and the Brazilian Society of Pathology (SBP).

The Brazilian Urology, Clinical Oncology, Radiation Oncology, and Pathology Societies selected 51 participants (25 clinical oncologists, 18 urologists, 5 radiation oncologists, and 3 pathologists) according to their recognized academic performance and extensive clinical experience.

The experts voted 104 multiple-choice questions during the meeting. An agreement $\geq 75 \%$ among the participants was considered a consensus. Otherwise, the most-voted answer was considered a recommendation. The option "abstention to vote" was available for those unable to choose an answer or with prohibitive conflicts of interest, and the vote was not counted. All answers considered 'consensus' or 'recommendation' were subjected to the best available evidence in the medical literature using Medline-PubMed and SciELO-Lilacs databases, and ranked according to a modified version of the Oxford Centre for Evidence-based Medicine-Levels of Evidence (CEBM 2020), as shown in Table 1.

\section{Results}

The main resolutions and recommendations of the First Brazilian Consensus on Penile Cancer are as follows. Additional file 1 contains all questions and voting results.

\section{Penile cancer risk factors}

Neonatal circumcision, the education of men regarding proper hygiene habits, smoking reduction, human papillomavirus (HPV) vaccination, and other actions in the prevention of sexually transmitted diseases reduce the risk for penile cancer and should be encouraged (consensus).

Phimosis is related to penile cancer and should not be considered physiologic after the age of 6 years (Dillner et al. 2000). Circumcision of newborns, though not in adulthood (Larke et al. 2011), reduces the risk of penile cancer (LE: 3a), especially invasive penile cancer (Larke et al. 2011). Circumcision does, however, protect against penile HPV infection in adults, especially in HIV-positive patients (Yuan et al. 2019), and helps to maintain adequate genital hygiene, which is also essential in reducing the risk of malignancy (Frisch et al. 1995) (LE: 3b).

HPV infection is strongly related to penile cancer (Backes et al. 2009) (LE: 2a). Preventative actions, such as the use of condoms and HPV vaccination, are essential. HPV vaccination reduces the risk of penile cancer ( $L E$ : $1 b$ ), as it results in a significant decrease in genital, precancerous, and malignant lesions (Giuliano et al. 2011). However, the recommendations for HPV vaccination may vary between different countries.

Currently, in Brazil, the quadrivalent HPV vaccine (6, 11,16 , and 18) is available for girls aged 9-14 years, boys aged 11-14 years, men and women from 9 to 26 years living with HIV/AIDS, individuals undergoing transplants of solid organs or bone-marrow transplantation, and cancer patients.

The expansion of the age range for boys' vaccination from the age of 9 years may better protect men and women, and reduce the spread of the HPV virus (recommendation, LE: 5) (Ministério da Saúde 2018). The HPV vaccination should not be considered mandatory for all cancer patients (consensus, LE: 5). The replacement of the quadrivalent HPV vaccine (6,
Table 1 Definition of levels of evidence (modified from CEBM 2020)

\begin{tabular}{ll}
\hline Level of evidence & Characteristics \\
\hline $1 \mathrm{a}$ & Systematic review with homogeneity of randomized clinical studies \\
$1 \mathrm{a}-$ & Systematic review with heterogeneity of randomized clinical studies \\
$1 \mathrm{~b}$ & Randomized clinical study \\
$1 \mathrm{~b}-$ & Non-randomized clinical study \\
$2 \mathrm{a}$ & Systematic review with homogeneity of cohort studies \\
$2 \mathrm{a}-$ & Systematic review with heterogeneity of cohort studies \\
$2 \mathrm{~b}$ & Individual cohort study \\
$3 \mathrm{a}$ & Systematic review with homogeneity of case-control studies \\
$3 \mathrm{a}-$ & Systematic review without homogeneity of case-control studies \\
$3 \mathrm{~b}$ & Individual case-control study \\
4 & Case-series \\
5 & Expert opinion \\
\hline
\end{tabular}


11,16 , and 18) to the nine-valent vaccine $(6,11,16,18,31$, $33,45,52$, and 58) would not be advisable in terms of public health (consensus, LE: 2a), because the latter does not show superior cost-effectiveness results ( $\mathrm{Ng}$ et al. 2018).
$50 \%$ of patients in Brazil present at an advanced stage at diagnosis (Favorito et al. 2008). Lack of knowledge is one of the main reasons that patients do not seek medical care earlier (Skeppner et al. 2012).

\section{PENILE CANCER RISK FACTORS: TAKE-HOME MESSAGE}

The incidence of penile cancer can significantly decrease with non-expensive actions:

- Neonatal circumcision;

- Tobacco cessation;

- Educational campaigns to inform the public of the importance of prevention of HPV and other sexually transmitted diseases through vaccination and use of condoms, proper genital hygiene and early detection of a suspected lesion.

However, health professionals should carefully evaluate this information, as the cost-effectiveness studies that were available at the time of this consensus meeting were performed mainly in developed countries, where penile cancer has a low prevalence and drug costs differ significantly from developing countries.

Smoking is a direct, independent, dose-related risk factor for penile cancer (LE: $3 b$ ), as is the consumption of products derived from tobacco (Hellberg et al. 1987; Harish and Ravi 1995). Heavy smokers (more than ten cigarettes per day) have twice the risk compared with light smokers and nonsmokers (Hellberg et al. 1987).

Educational campaigns for penile-lesion identification improve the early diagnosis of penile cancer and should be encouraged (consensus, LE: 5) as penile cancer has an easily recognizable slow-growing pattern. However, more than

\section{Penile cancer staging}

The recommendation for imaging examination in the staging of patients with penile SCC is chest computed tomography (CT) and abdominal and pelvic CT or magnetic resonance imaging (MRI) (recommendation, LE: 2b). CT helps to detect lymph-node involvement and systemic disease, with considerable sensitivity and high specificity in detecting metastatic lymph-node involvement (Zhu et al. 2008). MRI supports the investigation of local staging (Kayes et al. 2007). Bone metastases are uncommon and are usually associated with more advanced disease; therefore, patients should not routinely undergo bone scans unless they present signs and symptoms such as pain or increased alkaline phosphatase elevation (recommendation, LE: 4) (Braumann et al. 2015; Lal et al. 1999; Jacob et al. 1995). 


\section{PENILE CANCER STAGING: TAKE-HOME MESSAGE}

- Patients with penile cancer should undergo chest CT, abdominal and pelvic CT or MRI for staging;

- Bone scans should not be routinely employed.

\section{Treatment of localized disease: primary tumor}

Low-grade and low-stage penile carcinoma may benefit from organ-preserving penile procedures that can maintain normal appearance, organ function, and patient's quality of life without compromising oncologic outcomes. Conservative treatment encompasses surgery, topical therapy, laser therapy, and radiation therapy.

Table 2 describes penile cancer staging according to the American Joint Committee on Cancer Tumor, Node, Metastases (AJCC TNM) guidelines and classification of the histopathological grading system by the World Health Organization and the International Society of Uropathology (WHO/ ISUP) (Paner et al. 2018; Cubilla et al. 2018).

\section{Tis and Ta tumors}

The best conservative treatment of primary penile carcinoma in situ (Tis) is topical therapy (recommendation, LE: $2 b$ ). The use of topical 5-fluorouracil (5-FU) or imiquimod can provide from $40.0 \%$ to $73.7 \%$ complete response (Alnajjar et al. 2012; Lucky et al. 2015), with circumcision performed before therapy (Lucky et al. 2015). Patients presenting with non-invasive localized SCC (Ta) should be treated by partial glansectomy and resurfacing (recommendation, LE: 4). As most penile verrucous carcinomas are present in the glans, they have a slow progression and rarely present metastatically (Chuanyu et al. 2011; Li et al. 2015).

\section{T1 tumors}

Patients with T1aG1-2 should undergo glansectomy with grafting (recommendation, LE: 4), as this procedure can achieve 92\% disease-specific survival (O'kane et al. 2011). The best conservative treatment of T1bG3 is glansectomy with reconstruction (recommendation, LE: 4), with which sexual function is preserved (Pietrzak et al. 2004).
Therefore, patients presenting with Tis, Ta, and T1 G1-3 disease may benefit from conservative treatment. However, they have a higher risk of local recurrence, and physicians must closely monitor these patients through follow-up, especially when presenting perineural invasion, Tis, positive definitive margins, and high-grade tumors (Albersen et al. 2018). Besides, organ-sparing surgery does not provide a significant difference in overall survival compared with total or partial penectomy (Lindner et al. 2019; Djajadiningrat et al. 2014a, b). In the case of local recurrence after conservative treatment, the best option is partial amputation (consensus, LE: $2 \mathrm{~b}$ ), which provides a high local-control rate (94\%) (Lont et al. 2006), a low recurrence rate (approximately $5 \%$ ), and the ability to maintain organ function (Leijte et al. 2008).

\section{$\mathrm{T} 2, \mathrm{~T} 3$, and $\mathrm{T} 4$ tumors}

Partial amputation is also the best way to treat $\mathrm{T} 2$ disease when restricted to the corpus spongiosum/glans (consensus, LE: $2 b$ ) and T2/T3 invading the corpora cavernosa/urethra (recommendation, LE: 2b) (Ornellas et al. 2008). Partial amputation shows a significant 5-year local recurrence-free rate of approximately $60 \%$ (Lont et al. 2006), and $77 \%$ and $67 \%$ 5-year and 10-year survival rates, respectively (Kamel et al. 2018).

The best way to treat extended $\mathrm{T} 4$ tumors invading neighboring structures is total amputation/emasculation (recommendation, LE: 2b) (Ornellas et al. 2008). Neoadjuvant chemotherapy followed by surgery, if responsive, could be an option (recommendation, LE: 4), especially for patients with unresectable disease, yielding a 56\% survival rate (Leijte et al. 2007a, b).

The best treatment for local recurrence after radical treatment of the primary lesion is total amputation (recommendation, LE: $2 b$ ), providing a less than $5 \%$ recurrence rate (Djajadiningrat et al. 2014a, b; Veeratterapillay et al. 2015). 
Table 2 Staging according to tumor-node-metastasis (TNM) classification and histopathological grading system (Paner et al. 2018; Cubilla et al. 2018)

\section{T: Primary tumor}

Tis

$\mathrm{Ta}$

T1

$\mathrm{T} 2$

T3

$\mathrm{T} 4$

$c N$ : Clinical loco-regional lymph nodes

$\mathrm{cNx}$

$\mathrm{cNO}$

$\mathrm{cN} 1$

$\mathrm{cN} 2$

$\mathrm{cN} 3$

pN: Pathological loco-regional lymph nodes

$\mathrm{pNx}$

pNO

$\mathrm{pN} 1$

$\mathrm{pN} 2$

$\mathrm{pN} 3$

M: Distant metastasis

M0

M1

Stage

0

1

2

3

4

Histopathological grading system

Gx

G1

G2

G3-4
Carcinoma in situ

Non-invasive localized SCC, broadly extending invasion without destructive invasion

Tumor invades the subepithelial tissue layer in T1a: shows no lymphovascular invasion or the glans, foreskin, or shaft regions perineural invasion and is not poorly differentiated

T1b: shows lymphovascular invasion or perineural invasion or is poorly differentiated

Tumor invades the corpus spongiosum

Tumor invades the corpus cavernosum

Tumor invades other adjacent structures

Regional lymph nodes cannot be evaluated

No visibly enlarged or altered inguinal lymph nodes on physical examination

Palpable and mobile unilateral inguinal lymph nodes

Bilateral or multiple mobile and palpable inguinal lymph nodes

Palpable and fixed inguinal mass or unilateral or bilateral pelvic lymphadenopathy

Regional lymph nodes cannot be evaluated

No metastatic regional lymph nodes

Up to two unilateral inguinal lymph-node metastases without extranodal extension

More than two unilateral inguinal lymph-node metastases without extranodal extension

Extra-capsular extension or unilateral or bilateral pelvic lymph nodes

Absence of distant metastasis

Presence of distant metastasis

Tis or Ta, N0, M0

T1a, N0, M0

$\mathrm{T} 1 \mathrm{~b}$ or $\mathrm{T} 2$ or $\mathrm{T} 3, \mathrm{~N} 0, \mathrm{M} 0$

T1-3, N1, M0 or T1-3, N2, M0

$\mathrm{T} 4$, any $\mathrm{N}, \mathrm{M} 0$ or any $\mathrm{T}, \mathrm{N} 3, \mathrm{M} 0$ or any $\mathrm{T}$, any $\mathrm{N}, \mathrm{M} 1$

Histopathological grading cannot be evaluated

Well-differentiated

Moderately differentiated

Poorly differentiated/undifferentiated 


\section{TREATMENT OF LOCALIZED DISEASE - PRIMARY TUMOR: TAKE-HOME} MESSAGE

- Patients with localized penile cancer may benefit from organ-preserving treatment, chosen according to primary tumor classification;

- Topical therapy should be the choice of treatment for Tis tumors. Partial glansectomy and resurfacing is used for Ta tumors, glansectomy with grafting for T1aG1-2, and glansectomy with reconstruction for T1bG3;

- All patients undergoing conservative treatment must be closely monitored as they present a considerable risk of recurrence;

- Partial amputation is recommended in the case of tumor recurrence after conservative treatment, and primary treatment of $\mathrm{T} 2$ and $\mathrm{T} 3$ tumors. $\mathrm{T} 4$ tumors should be treated with total amputation.

\section{Treatment of locally advanced disease: lymph-node involvement}

Lymph-node metastasis is the most important independent predictor of survival in patients with penile carcinoma (da Costa et al. 2015; Hegarty et al. 2006; Horenblas and Tinteren 1994). The main prognostic factors for inguinal lymph-node metastases used to indicate lymphadenectomy are $\geq \mathrm{pT} 1 \mathrm{~b}$ stage, microscopic lymphatic invasion, perineural invasion, invasion $>0.5 \mathrm{~mm}$, and palpable lymph nodes after primary tumor resection and appropriate antibiotic therapy (consensus, LE: 2b) (Slaton et al. 2001; Ficarra et al. 2006; Velazquez et al. 2008).

Patients may present high risk or low risk of lymphnode involvement. High immunohistochemical expression of p53, MMP2, and MMP9, and low Ki-67 expression, the infiltrating growth pattern rather than growth by displacement ("pushing") pattern, and unfavorable histology (usual type, basaloid, adenosquamous, and mixed and sarcomatoid squamous cell carcinoma) are variables associated with a higher risk of regional lymph-node metastases (Gunia et al. 2012; Zhu et al. 2007; Cubilla et al. 2001).
These characteristics should be taken into account in the indication of lymphadenectomy whenever possible (recommendation, LE: 4). Intraepithelial neoplasms (Ta), pT1a stage, papillary or warty tumors, and tumors with noninvasive vertical exophytic growth are low-risk factors for inguinal lymph-node involvement that contribute to the contraindication for lymphadenectomy (consensus, LE: 2b) (Ornellas et al. 2008).

Healthcare professionals should consider early inguinal lymphadenectomy (2-6 weeks after primary tumor surgery), only for patients at high risk of lymph-node involvement (consensus, LE: $2 b$ ). This procedure significantly increases the 5- and 10-year survival rates in up to $91 \%$ of patients compared with $13 \%$ in cases of delayed lymphadenectomy (Kroon et al. 2005; McDougal 1995; Gulia et al. 2009; Ornellas et al. 2008). However, early lymphadenectomy is recommended in certain specific cases (recommendation, LE: $2 b$ ), such as in patients with uncertain adherence to the long-term follow-up needed after treatment of the primary tumor. This is because recurrence is possible up to 25 years after treatment, and early lymphadenectomy significantly improves patients' survival (Ornellas et al. 2008). 
Aspiration biopsy of suspected inguinal lymph nodes, guided by imaging methods, is a safe method for the investigation of lymph-node involvement. It may aid diagnosis, showing high sensitivity and specificity $(87.3 \%$ and $99.9 \%$, respectively) (Djajadiningrat and Teerst 2014), but it is not routinely recommended (recommendation, LE: $2 b$ ).

Radical inguinal lymphadenectomy should always be bilateral owing to presymphyseal lymphatic crossover (Park et al. 1994) and when imaging shows more than 50\% bilateral inguinal drainage (Spiess et al. 2007) (consensus, LE: 4). An exception can be made when the sentinel lymph-node dynamic biopsy (BDLS) is negative on one side (recommendation, LE: 4). In such cases, patients must rigorously attend follow-ups, as there is a risk of occult micrometastasis in patients with negative BDLS (Spiess et al. 2007). The BDLS should be performed only at referral centers with trained staff (consensus, LE: $2 b$ ), as it may present a high rate of false-negative results (Leijte et al. 2007a).

Patients with only one affected inguinal lymph node without extra-capsular extension and size $<4.0 \mathrm{~cm}$ have a low risk of pelvic involvement (Lont et al. 2007); therefore, they should follow active surveillance and no other surgical procedure (recommendation, LE: $2 \mathrm{~b}$ ). Inguinal lymph-node dissection should be the next step for patients with unilateral mobile lymph-node enlargement $\geq 4 \mathrm{~cm}$, and biopsyconfirmed lymph-node metastatic disease (recommendation, LE: 5). Pelvic lymphadenectomy is always indicated in the case of two or more affected inguinal lymph nodes or in the presence of extra-capsular extension (consensus, LE: 2b), as the risk of pelvic lymph-node involvement is significant (Lont et al. 2007; Zargar-Shoshtari et al. 2015; Ravi 1993). Patients with resectable pelvic lymph-node enlargement, identified on imaging during staging, should also undergo pelvic lymphadenectomy (consensus, LE: $2 b$ ). Unilateral inguinal lymphadenectomy is an acceptable recommendation, supported by low evidence publication (recommendation, LE: 4) (Tsaur et al. 2015). Bilateral pelvic lymph-node dissection (PLND) is always the first choice in patients with demonstrable unilateral metastatic disease as it shows more prolonged overall survival versus ipsilateral PLND (ZargarShoshtari et al. 2016).

The best immediate approach for patients with bilateral or fixed inguinal lymph-node enlargement without pelvic lymph-node enlargement, but also for those with fixed, stony or unresectable pelvic lymph-node enlargement identified on imaging, is neoadjuvant chemotherapy (conversion chemotherapy) (consensus, LE:1b-), with a cisplatin-based triple scheme (with taxane) (consensus, LE: 1b-). This approach shows statistically significant improvement in median progression-free survival and overall survival (Pagliaro et al. 2010; Xu et al. 2019), with a 50.0\% response rate and $36.7 \%$ long-term progression-free survival (Pagliaro et al. 2010). For non-responsive patients, the palliative approach should be inguinal lymphadenectomy and radiotherapy (recommendation, LE: $1 b-$ ).

Patients with unilateral mobile lymph-node enlargement $\geq 4 \mathrm{~cm}$ undergoing neoadjuvant chemotherapy who have residual disease in one or more inguinal lymph nodes should undergo pelvic lymphadenectomy (consensus, LE: 5), as the chance of pelvic lymph-node involvement is high (Lont et al. 2007; Zargar-Shoshtari et al. 2015; Ravi 1993). For patients with resectable cN3 disease who lack a complete or partial clinical response to neoadjuvant chemotherapy, but show no disease progression during chemotherapy, the next approach should be primary tumor resection and inguinal and pelvic lymphadenectomy (consensus, LE: 2b). Patients with $\mathrm{cN} 2$ or $\mathrm{cN} 3$ disease with clinical response to neoadjuvant chemotherapy with ypN and residual disease should receive radiotherapy as adjuvant treatment (recommendation, LE: 2b) (Xu et al. 2019).

To evaluate the treatment response, to avoid continuing chemotherapy if the patient is not responding, or to change the planned treatment if the disease progresses, upper abdomen and chest CT should be used for distance disease assessment during or after neoadjuvant chemotherapy (consensus, LE: 5). MRI or pelvic CT is the most suitable imaging modality for loco-regional response evaluation of neoadjuvant chemotherapy (recommendation, LE: 5), as it can show deep lymph nodes and masses in the pelvis and retroperitoneum (Mao et al. 2014).

Patients with $\mathrm{pN} 1$ disease who have undergone primary tumor resection and inguinal lymphadenectomy without neoadjuvant treatment should receive only chemotherapy as adjuvant treatment (recommendation, LE: 4) as it prevents disease progression and improves 5-year overall survival (Pizzocaro et al. 1997). Combination with radiotherapy may only benefit patients with extensive disease (Choo et al. 2019). Patients not undergoing neoadjuvant treatment, but who have inguinal and pelvic lymphadenectomy and metastases in pelvic lymph nodes with bilateral inguinal lymphnode involvement or extranodal extension, should receive adjuvant treatment with chemotherapy and radiotherapy (recommendation, LE: $2 \mathrm{~b}$ ) with a cisplatin-based triple scheme (with taxane) (recommendation, LE: $2 b$ ), even if the evidence is still controversial. Adjuvant treatment improves overall survival (Sharma et al. 2015), but also shows no difference compared with no treatment (Kim et al. 2018; Choo et al. 2019). 


\section{TREATMENT OF LOCALLY ADVANCED DISEASE - LYMPH-NODE \\ INVOLVEMENT: TAKE-HOME MESSAGE}

- Lymph-node involvement is the most important predictor of survival in patients with penile cancer;

- All patients presenting as high risk and those not found to be compromised at follow up should undergo early inguinal lymphadenectomy;

- Patients with two or more affected inguinal lymph nodes, or in the presence of extracapsular extension, and patients with resectable pelvic lymph-node enlargement, should undergo pelvic lymphadenectomy;

- Neoadjuvant cisplatin-based chemotherapy should be considered for patients with bilateral or fixed inguinal lymph-node enlargement, and for fixed, stony or unresectable pelvic lymph-node enlargement;

- Those not receiving neoadjuvant chemotherapy should be evaluated for adjuvant chemotherapy, and radiotherapy in the case of extensive disease.

\section{Unresectable or relapsed tumors}

The recommendation for patients with local recurrence infiltrating perineum without lymph-node involvement is neoadjuvant chemotherapy and surgical re-approach whenever possible (recommendation, LE: 4). This approach should also be considered for patients with advanced local recurrence and a unilateral or bilateral inguinal lymph-node mass, with or without vascular involvement (consensus, LE: 4). Chemotherapy yields a $60 \%$ rate of downstaging for unresectable tumors, and surgery on responders increases their 5 -year overall survival by $32 \%$ (Leijte et al. 2007a, b).
Patients with local recurrence after chemotherapy/radiotherapy treatment without a prior surgical approach should undergo a surgical approach with the possibility of colostomy and cystostomy (consensus, LE: 5).

In first-line therapy for unresectable, recurrent and/or metastatic penile cancer, the standard therapy is systemic combination chemotherapy with cisplatin, ifosfamide, and paclitaxel (TIP) (recommendation, LE: 1b-), as well as other combinations of cisplatin, such as irinotecan, docetaxel, and fluorouracil (Nicholson et al. 2013; Theodore et al. 2008). 


\section{UNRESECTABLE OR RELAPSED TUMORS: TAKE-HOME MESSAGE}

Unresectable or relapsed tumors should be treated with cisplatin-based chemotherapy and surgery whenever it is possible.

\section{Relapsed disease without the possibility of local rescue/metastatic disease}

Systemic progression in penile cancer is beyond cure. Patients presenting with visceral metastasis should receive definitive palliative chemotherapy, whether they have a local recurrence or advanced tumors with a unilateral or bilateral fixed inguinal lymph-node mass, with or without vascular involvement but with visceral metastasis, or locally treated and controlled disease, but with visceral recurrence, or visceral recurrence after local surgical resection, chemo- and/ or radiotherapy (consensus, LE: 1b-) (Nicholson et al. 2013; Theodore et al. 2008). The response rate of chemotherapy in advanced disease is low (Hakenberg et al. 2006), and a partial response may be achieved in a very limited number of patients (Haas et al. 1999; Pizzocaro et al. 2009). Patients presenting with local and visceral recurrence after surgical resection, first- and second-line chemotherapy, and/or radiotherapy should receive palliative care (consensus, LE: 5).

Currently, the role of anti-epidermal growth factor receptor (anti-EGFR) targeted therapy (cetuximab, panitumumab, and dacomitinib) in the treatment of advanced penile cancer is investigational (recommendation, LE: 1b-) as the available literature is still limited (Necchi et al. 2018; Carthon et al. 2014; Brown et al. 2014; Buonerba et al. 2016). Anti-EGFR is an option in unresectable, relapsed, and/or metastatic cancer as a second-line treatment, associated or not associated with chemotherapy, after TIP/TPF failure (recommendation, LE: 4), showing a trend to a higher response rate compared with other chemotherapy regimens (Buonerba et al. 2016).

\section{RELAPSED DISEASE WITHOUT THE POSSIBILITY OF LOCAL RESCUE/METASTATIC DISEASE: TAKE-HOME MESSAGE}

Penile cancer patients with visceral metastasis should receive palliative care, based on chemotherapy. 


\section{Surgical aspects}

Multimodal therapy is a good option for the treatment of advanced disease in penile cancer. The best approach after chemotherapy is surgery (consensus, LE: 2a-), providing a better chance for more extensive organ preservation by reducing the tumor mass. Compared with brachytherapy, surgery yields a lower overall recurrence rate (Hasan et al. 2015). However, surgeons should not consider hemipelvectomy and/or hemicorporectomy (recommendation, LE: 5).

The best surgical treatment option for urinary-tract reconstruction in disseminated metastatic disease is cystostomy (recommendation, LE: 5). Surgeons must avoid an ileal conduit for urinary-tract reconstruction/diversion in patients receiving multimodal therapy (recommendation, LE: 5). In locally unresectable disease with involvement of the posterior urethra and/or prostate, perineal urethrostomy should also be avoided as a means of urinary diversion (consensus, LE: $2 b$ ) owing to the high risk of stenosis after radiotherapy (Myers et al. 2011).

Chemoradiotherapy can provide adequate local control for resectable tumors that failed surgical resection (Langsenlehner et al. 2008) (recommendation, LE: 2b).
Radiotherapy can be the primary treatment modality in patients with small tumors (less than $4 \mathrm{~cm}$ ), whereas surgery is a salvage procedure. Contact brachytherapy is used in patients presenting with T1 G1-2 tumors smaller than $4 \mathrm{~cm}$ (consensus, LE: 4), as a penile-preservation technique with significant tumor control and organ preservation (MarbanOrejas et al. 2020). Interstitial brachytherapy (consensus, LE: 2a-) treats T1 G1 to G4 and T2 tumors smaller than $4 \mathrm{~cm}$. This technique presents an $83 \%$ rate of local control, with a 5-year local, regional recurrence-free survival (Rouscoff et al. 2014; Crook et al. 2010), and 5-year overall and disease-free survival similar to penectomy (Hasan et al. 2015). Teletherapy is also an option for radiotherapy (consensus, LE: 2 b), with a $62 \%$ 5-year local control rate and a $40 \%$ rate for penile-preservation (Azrif et al. 2006).

Elective irradiation of inguinal and pelvic lymph nodes is never indicated (consensus for T1 G1-2; recommendation for T1 G3-4 and T2, LE: 2a), because surgery has superior benefits in terms of oncological outcomes in the case of lymph-node involvement, especially in high-grade tumors, and radiotherapy does not improve recurrence or survival rates (Robinson et al. 2018).

\section{SURGICAL ASPECTS: TAKE-HOME MESSAGE}

Patients with advanced penile cancer should receive neoadjuvant chemotherapy and surgery; and chemoradiotherapy for surgical resection failure.

\section{Radiotherapy}

SCC penile carcinoma is a radiosensitive tumor, enabling radiotherapy to provide treatment and organ preservation. Radiotherapy is indicated in case of patient preference and/ or inoperability for comorbidities, in T1 or T2 tumors, in tumors less than $4 \mathrm{~cm}$ (recommendation, LE: $2 \mathrm{~b}$ ), with significant local control, and up to $87 \%$ of cases with organ preservation (Azrif et al. 2006; Crook et al. 2007; Cordoba et al. 2016). Such patients should undergo prostectomy before radiotherapy whenever possible (consensus, LE: 5), making the tumor more visually evident, avoiding complications, such as necrosis.
Patients with T1 G3-4 or T2 tumors smaller than $4 \mathrm{~cm}$ receiving radical radiotherapy should also receive chemotherapy (recommendation, LE: 4), thereby improving the chances of disease control (Chhabra et al. 2014). It is never indicated for patients with T1 G1-2 tumors smaller than $4 \mathrm{~cm}$ (consensus, LE: 5), as the evidence for a benefit in penile cancer is not available and limited in other cancer sites (Shylasree et al. 2011).

Patients with T1-T2 tumors larger than $4 \mathrm{~cm}$ undergoing radical radiotherapy should always receive elective irradiation of inguinal and pelvic lymph nodes, in concomitance with chemotherapy (recommendation, LE: $2 b$ ). This prevents extranodal extension and disease recurrence (Ravi 1993). Teletherapy is an acceptable radical-purpose 
radiotherapy technique (recommendation, LE: 5), but patients with tumors that size should not undergo interstitial brachytherapy (recommendation, LE: $2 \mathrm{~b}$ ) as the risk of recurrence is high (de Crevoisier et al. 2009). This technique can be used to increment the doses of teletherapy (recommendation, LE: 5). be treated (recommendation, LE: $2 \mathrm{~b}$ ). The ideal technique is modulated intensity radiotherapy (IMRT) combined with imaging-guided radiotherapy (IGRT), based on the evaluation of IMRT from prostate cancer patients, with lower toxicity in pelvic organs compared with RT3D (Viani et al. 2019) (recommendation, LE: 2b).

\section{RADIOTHERAPY: TAKE-HOME MESSAGE
- Radiotherapy is a valid option for primary treatment of penile cancer patients with
small T1 or T2 tumors (less than 4cm), refusing or with contraindication for surgery;
- Patients with T1 G3-4 or T2 tumors should also receive chemotherapy;
- T1-T2 tumors larger than 4cm, and all T3-T4 tumors: radical radiotherapy, elective
irradiation of inguinal and pelvic lymph nodes, and chemotherapy;
- Patients with compromised surgical margin may benefit from adjuvant radiotherapy.}

Patients with T3-T4 tumors who receive radical-purpose radiotherapy should also receive elective irradiation of inguinal and pelvic lymph nodes (recommendation, LE: 2 b), delivered concomitantly with chemotherapy (consensus, LE: 2b). Radiation therapy alone provides a low local-control rate (approximately $40 \%$ ) and only a $38 \%$ penile-preservation rate (Zouhair et al. 2001). Interstitial brachytherapy is not an acceptable technique for such patients (consensus, LE: 5), nor is teletherapy (recommendation, LE: 5) or teletherapy with dose-enhanced interstitial brachytherapy (recommendation, LE: 5).

Adjuvant radiotherapy is indicated for patients with a compromised surgical margin (recommendation, LE: 5), and for those with $\mathrm{cN} 2$ disease not receiving neoadjuvant treatment and undergoing inguinal and pelvic lymph-node dissection, if $\geq \mathrm{pN} 2$ (recommendation, LE: $2 \mathrm{~b}$ ). Adjuvant radiotherapy improves overall survival in patients with advanced disease with lymph-node involvement (Tang et al. 2017; Winters et al. 2018) and decreases recurrence rates (Tang et al. 2017). pT3-pT4N0 with free margins is not an indication for adjuvant radiotherapy in penile cancer (consensus, LE: 2b) as it does not improve oncological outcomes compared with surgery alone (Burt et al. 2014).

Conformational radiotherapy (RT3D) is the minimum technique for administering the radiation dose when radical teletherapy is indicated (with or without chemotherapy) in which lymph nodes will (consensus, LE: 2b) or will not

\section{Follow-up}

Penile cancer has a significant impact on patients' quality of life, including social, psychological, and sexual aspects (Drager et al. 2017; Ficarra et al. 2000). Therefore, psychological support should always be offered to patients after diagnosis (consensus, LE: 2b).

More than $90 \%$ of penile cancer recurrence occurs within the first 5 years after primary tumor treatment, especially during the first 2 years (Horenblas et al. 1993; Leijte et al. 2008). Follow-up of asymptomatic patients consists of anamnesis, clinical examination, and imaging every 3 months for the first 2 years, and every 6 months until the fifth year (recommendation, LE: 2b). The choice of imaging method depends on lymph-node involvement. Patients treated for early penile cancer (NO) are evaluated by US and Rx (recommendation, LE: 4) (Yamashita and Ogawa 1989), and patients with N1-N3 disease by CT and MRI (recommendation for N1, LE: 4; consensus for N2-3, LE: 4) (de Kerviler et al. 1995).

The follow-up of patients with advanced penile cancer (unresectable/inoperable) should be established individually, with referral to palliative care as needed (consensus, LE: 5). 


\section{FOLLOW-UP OF PENILE CANCER PATIENTS: TAKE-HOME MESSAGE}

- Psychological support should be provided to all patients;

- Follow up must take place every three months for the first two years, and every six months until the fifth year;

- US and Rx for patients without lymph-node involvement;

- CT and MRI for patients with lymph-node involvement.

\section{Bone therapy}

Bone is a rare distant metastasis site for penile cancer, and the evidence for management is low. Clinical decisions are made based on extrapolation of data from other solid tumors with a high incidence of bone metastasis, such as prostate cancer.

Bone-modifying agents should be indicated for all penile cancer patients with bone metastasis (without clinical contraindications, e.g., allergies, kidney failure, or others) (consensus, LE: 5), as it decreases or delays skeleton-related events (Saad et al. 2004). There is no preference among the bone-modifying agents (recommendation, LE: 5). Even if no comparative study in penile cancer patients is available, denosumab shows a trend toward superiority (Fizazi et al. 2011). The recommended dose and frequency of zoledronic acid are $4 \mathrm{mg}$ IV every 4 weeks (recommendation, LE: 5). For patients using denosumab, $120 \mathrm{mg}$ SC should be administered every 4 weeks (consensus, LE: 5). Therapy with bone-modifying agents is used without a limited duration or until a significant and/or intolerable adverse event occurs (consensus, LE: 5).

\section{BONE THERAPY: TAKE-HOME MESSAGE}

- Bone-modifying agents are indicated for all penile cancer patients with bone metastasis until an adverse event occurs;

- There is no preference between drugs;

- Zoledronic acid, 4mg I.V., every four weeks;

- Denosumab, $120 \mathrm{mg}$ I.V., every four weeks. 


\section{Conclusion}

Penile carcinoma is a challenging disease, with a high incidence in low- and middle-income countries, with limited health system resources and populations with low education hampering more efficient management. This consensus statement delivers an important decision-making orientation regarding penile carcinoma, in which improvement of care is particularly required. The evidence levels are generally low owing to the low incidence of the disease in developed countries and, consequently, the lack of large, randomized investigations. More clinical studies are needed, and whenever possible, specialists should refer patients to clinical trials.

Acknowledgements The authors would like to thank the panellists who participated in this consensus statement: Dr Adriano Gonçalves e Silva, Dr Alisson Borges, Dr Ana Paula Garcia, Dr André Deeke Sasse, Dr André Fay, Dr Antônio Augusto Ornellas de Souza, Dr Antônio Carlos de Lima Pompeo, Dr Carlos Eugênio Lira Tenório, Dr Denis Leonardo Fontes Jardim, Dr Diogo Augusto Rodrigues da Rosa, Dr Evanius Garcia Wiermann, Dr Fabio de Lima Costa Faustino, Dr Felipe da Silva Marinho, Dr Felipe Dubourcq de Barros, Dr Felipe Monnerat Lott, Dr Fernando Korkes, Dr Fernando Nunes Galvão de Oliveira, Dr Fernando Sabino Marques Monteiro, Dr Francisco Sergio Moura S. do Nascimento, Dr Franz Santos de Campos, Dr Giuliano Amorim Aita, Dr Giullianno Lopes de Moura, Dr Guilherme Antonio Veloso Coaracy, Dr Gyl Eanes Barros da Silva, Dr Igor Morbeck, Dr Isabela Werneck, Dr Jonathan Doyun Cha, Dr José Augusto Rinck Jr., Dr José Fernando Bastos Moura, Dr Karine Martins da Trindade, Dr Leonardo Atem Gonçalves de A. Costa, Dr Manuel Caitano Maia, Dr Marcelo Langer Wroclawski, Dr Paulo Lages, Dr Rodrigo José de Vasconcelos Valença, Dr Rodrigo Sousa Madeira Campos, Dr Vinicius Carrera Souza, and Dr Volney Soares Lima. The authors would also like to thank Dr Mariana Matos, MD, for writing assistance, on behalf of Springer Healthcare. This manuscript was prepared according to the International Society for Medical Publication Professionals-Good Publication Practice for Communicating Company-Sponsored Medical Research: the GPP3 Guidelines.

Author contributions All authors were responsible for the conception of this consensus statement; they prepared the questions for voting, participated in the meeting and voting, performed the literature research, and critically reviewed this manuscript. They have all have read and approved the final version.

Funding Funding to support the expert meeting and the preparation of this manuscript was provided by LACOG-GU (Latin American Cooperative Oncology Group-Genitourinary). The authors take full responsibility for the content and conclusions stated in this manuscript.

\section{Compliance with ethical standards}

Conflict of interest Aluízio Gonçalves da Fonseca: none. Andrey Soares: Speaker fee: Janssen, Pfizer, Bayer, Novartis, Astra Zeneca, Astellas, Pierre-Fabre, Merck-Serono, Sanofi, Lilly, Merck Sharp \& Dohme, Roche, Bristol-Myers Squibb. Events Sponsorship: AstraZeneca, Pfizer, Astellas, Bristol-Myers Squibb, Merck Sharp \& Dohme, Bayer, Roche, Janssen, Merck Serono, Sanofi, Ipsen. Advisory Board: Astellas, Janssen, Roche, Bayer, Lilly, AstraZeneca, Novartis, Merck Sharp \& Dohme, Bristol-Myers Squibb, Pfizer. Research Funding: Bristol-Myers Squibb. Antonio Machado Alencar Jr.: None. Carlos
Heli Bezerra Leite: None. Diogo Assed Bastos: Research funding: Janssen, Astellas, Pfizer, Merck Sharp \& Dohme. Honouraria/Advisory Board: Janssen, Astellas, Bristol-Myers Squibb, Merck Sharp \& Dohme, Roche, Pfizer, Novartis, Bayer. Icaro Thiago de Carvalho: None. João Paulo Holanda Soares: Events sponsorship: Merck Sharp \& Dome, Bayer. Research Funding: Merck Sharp \& Dome, Beigene, Lilly, Nektar. José Ribamar Rodrigues Calixto: None. Katia Ramos Moreira Leite: None. Mário Ronalsa Brandão Filho: none. Ronald Wagner Pereira Coelho: Speaker fee: Roche. Sandro Roberto de A. Cavallero: Speaker fee: Janssen, Pfizer, Bayer, Novartis, AstraZeneca, Astellas, Amgen, Takeda, Merck Sharp \& Dohme, Roche, Bristol-Myers Squibb. Events Sponsorship: AstraZeneca, Pfizer, Astellas, BristolMyers Squibb, Merck Sharp \& Dohme, Bayer, Roche, Janssen. Advisory Board: Amgen, Janssen, Roche, Merck Sharp \& Dohme, Pfizer. Stênio de Cassio Zequi: Speaker fee: Bristol-Myers Squibb, Pfizer and AstraZeneca. Research funding: Merck Sharp \& Dohme. Events sponsorship: Astellas.

Open Access This article is licensed under a Creative Commons Attribution 4.0 International License, which permits use, sharing, adaptation, distribution and reproduction in any medium or format, as long as you give appropriate credit to the original author(s) and the source, provide a link to the Creative Commons licence, and indicate if changes were made. The images or other third party material in this article are included in the article's Creative Commons licence, unless indicated otherwise in a credit line to the material. If material is not included in the article's Creative Commons licence and your intended use is not permitted by statutory regulation or exceeds the permitted use, you will need to obtain permission directly from the copyright holder. To view a copy of this licence, visit http://creativecommons.org/licenses/by/4.0/.

\section{References}

Albersen M, Parnham A, Joniau S, Sahdev V, Christodoulidou M, Castiglione $\mathrm{F}$ et al (2018) Predictive factors for local recurrence after glansectomy and neoglans reconstruction for penile squamous cell carcinoma. Urol Oncol 36:141-146

Alnajjar HM, Lam W, Bolgeri M, Rees RW, Perry MJ, Watkin NA (2012) Treatment of carcinoma in situ of the glans penis with topical chemotherapy agents. Eur Urol 62:923-928

Azrif M, Logue JP, Swindell R et al (2006) External-beam radiotherapy in T1-2 N0 penile carcinoma. Clin Oncol (R Coll Radiol) 18:320-325

Backes DM, Kurman RJ, Pimenta JM, Smith JS (2009) Systematic review of human papillomavirus prevalence in invasive penile cancer. Cancer Causes Control 20:449-457

Braumann L, Tsagozis P, Wedin R, Brosjö O (2015) Femoral metastasis from penile carcinoma: report of 2 cases. Case Rep Urol 2015:583851

Brown A, Ma Y, Danenberg K et al (2014) Epidermal growth factor receptor-targeted therapy in squamous cell carcinoma of the penis: a report of 3 cases. Urology 83:159-165

Buonerba C, Di Lorenzo G, Pond G et al (2016) Prognostic and predictive factors in patients with advanced penile cancer receiving salvage ( 2 nd or later line) systemic treatment: a retrospective, Multi-Center Study. Front Pharmac 7:487

Burt LM, Shrieve DC, Tward JD (2014) Stage presentation, care patterns, and treatment outcomes for squamous cell carcinoma of the penis. Int J Radiat Oncol Biol Phys 88:94-100

Cardona CEM, García-Perdomo HA (2017) Incidence of penile cancer worldwide: systematic review and meta-analysis. Rev Panam Salud Publica 41:e117 
Carthon BC, Ng CS, Pettaway CA, Pagliaro LC (2014) Epidermal growth factor receptor-targeted therapy in locally advanced or metastatic squamous cell carcinoma of the penis. BJU Int 113:871-877

CEBM, The Centre for Evidence-Based Medicine (2009) Oxford Centre for Evidence-based Medicine - Levels of Evidence. Cebm. net. https://www.cebm.net/2009/06/oxford-centre-evidencebased-medicine-levels-evidence. Accessed 10 Sept 2020

Chhabra A, Schwartz D, Leaf A, Karanikolas N, Weiss JP, Schreiber D (2014) Neoadjuvant concurrent chemoradiation for curative treatment of penile squamous cell carcinoma. Case Rep Oncol Med 2014:479376

Choo R, Nehra A, Zattoni F, Pagliaro LC, Karnes RJ (2019) Is there any benefit in adding postoperative adjuvant concurrent radiotherapy and chemotherapy for penile cancer with regional lymph node metastasis? Minerva Urol Nefrol. https://doi.org/10.23736/ S0393-2249.19.03387-3

Chuanyu S, Ke X, Jie Z, Guowei X, Zujun F, Qiang D (2011) Surgical treatment for 11 cases of penile verrucous carcinoma. Ann Dermatol 23(Suppl 3):S346-S349

Cordoba A, Escande A, Lopez S et al (2016) Low-dose brachytherapy for early stage penile cancer: a 20-year single-institution study (73 patients). Radiat Oncol 27(11):96

Crook J, Grimard L, Esche B, Pond G (2007) MP-21.03: penile brachytherapy: results for 60 patients. Urology 70:161

Crook J, Jezioranski J, Cygler JE (2010) Penile brachytherapy: technical aspects and postimplant issues. Brachytherapy 9:151-158

Cubilla AL, Reuter V, Velazquez E et al (2001) Histologic classification of penile carcinoma and its relation to outcome in 61 patients with primary resection. Int J Surg Pathol 9:111-120

Cubilla AL, Velazquez EF, Amin MB, Epstein J, Berney DM, Corbishley CM, Members of the ISUP Penile Tumor Panel (2018) The World Health Organization 2016 classification of penile carcinomas: a review and update from the International Society of Urological Pathology expert-driven recommendations. Histopathology 72(6):893-904

da Costa WH, Rosa de Oliveira RA, Santana TB et al (2015) Prognostic factors in patients with penile carcinoma and inguinal lymph node metastasis. Int J Urol 22(7):669-673

de Crevoisier R, Slimane K, Sanfilippo N et al (2009) Long-term results of brachytherapy for carcinoma of the penis confined to the glans (N- or NX). Int J Radiat Oncol Biol Phys 74:1150-1156

de Kerviler E, Ollier P, Desgrandchamps F et al (1995) Magnetic resonance imaging in patients with penile carcinoma. Br J Radiol 68:704-711

Dillner J, von Krogh G, Horenblas S, Meijer CJ (2000) Etiology of squamous cell carcinoma of the penis. Scand J Urol Nephrol Suppl 205:189-193

Djajadiningrat RS, Teertstra HJ, van Werkhoven E, van Boven HH, Horenblas S (2014) Ultrasound examination and fine needle aspiration cytology-useful for followup of the regional nodes in penile cancer? J Urol 191(3):652-655

Djajadiningrat RS, van Werkhoven E, Meinhardt W et al (2014) Penile sparing surgery for penile cancer-does it affect survival? J Urol 192:120-125

Drager DL, Protzel C, Hakenberg OW (2017) Identifying psychosocial distress and stressors using distress-screening instruments in patients with localized and advanced penile cancer. Clin Genitourin Cancer 15:605-609

Favorito LA, Nardi AC, Ronalsa M, Zequi SC, Sampaio FJB, Glina S (2008) Epidemiologic study on penile cancer in Brazil. International Braz J Urol 34:587-593

Ficarra V, Righetti R, D'Amico A et al (2000) General state of health and psychological well-being in patients after surgery for urological malignant neoplasms. Urol Int 65:130-134

Ficarra V, Zattoni F, Artibani W et al (2006) Nomogram predictive of pathological inguinal lymph node involvement in patients with squamous cell carcinoma of the penis. J Urol 175:1700-1704 ((discussion 1704-5))

Fizazi K, Carducci M, Smith M et al (2011) Denosumab versus zoledronic acid for treatment of bone metastases in men with castration-resistant prostate cancer: a randomized, double-blind study. Lancet 377(9768):813-822

Frisch M, Friis S, Kjaer SK, Melbye M (1995) Falling incidence of penis cancer in an uncircumcised population (Denmark 194390). BMJ 311:1471

Giuliano AR, Palefsky JM, Goldstone S et al (2011) Efficacy of quadrivalent HPV vaccine against HPV infection and disease in males. N Engl J Med 364:401-411

GLOBOCAN Cancer today. https://gco.iarc.fr/today/online-analysismulti-bars. Accessed 20 Dec 2019

Gulia AK, Mandhani A, Muruganandham K, Kapoor R, Ansari MS, Srivastava A (2009) Impact of delay in inguinal lymph node dissection in patients with carcinoma of penis. Indian J Cancer 46:214-218

Gunia S, Kakies C, Erbersdobler A, Hakenberg OW, Koch S, May M (2012) Expression of p53, p21 and cyclin D1 in penile cancer: p53 predicts poor prognosis. J Clin Pathol 65:232-236

Haas GP, Blumenstein BA, Gagliano RG et al (1999) Cisplatin, methotrexate and bleomycin for the treatment of carcinoma of the penis: a Southwest Oncology Group study. J Urol 161:1823-1825

Hakenberg OW, Nippgen JB, Froehner M, Zastrow S, Wirth MP (2006) Cisplatin, methotrexate and bleomycin for treating advanced penile carcinoma. BJU Int 98:1225-1227

Harish K, Ravi R (1995) The role of tobacco in penile carcinoma. $\mathrm{Br}$ J Urol 75:375-377

Hasan S, Francis A, Hagenauer A et al (2015) The role of brachytherapy in organ preservation for penile cancer: a meta-analysis and review of the literature. Brachytherapy 14:517-524

Hegarty PK, Kayes O, Freeman A et al (2006) A prospective study of 100 cases of penile cancer managed according to EAU guidelines. BJU Int 98:526-531

Hellberg D, Valentin J, Eklund T, Nilsson S (1987) Penile cancer: is there an epidemiological role for smoking and sexual behavior? Br Med J (Clin Res Ed) 295:1306-1308

Horenblas S, van Tinteren H (1994) Squamous cell carcinoma of the penis. IV. Prognostic factors of survival: analysis of tumor, nodes and metastasis classification system. J Urol 151:1239-1243

Horenblas S, van Tinteren H, Delemarre JF, Moonen LM, Lustig V, van Waardenburg EW (1993) Squamous cell carcinoma of the penis. III. Treatment of regional lymph nodes. J Urol 149:492-497

Jacob R, Jyothirmayi R, Kumar A, Nair MK, Rajan B (1995) Case report: spinal metastasis from carcinoma of the penis. Brit $\mathrm{J}$ Radiol 68:1367-1368

Kamel MH, Tao J, Su J et al (2018) Survival outcomes of organ sparing surgery, partial penectomy, and total penectomy in pathological T1/T2 penile cancer: report from the National Cancer Data Base. Urol Oncol 36:82.e7-82.e15

Kayes O, Minhas S, Allen C, Hare C, Freeman A, Ralph D (2007) The role of magnetic resonance imaging in the local staging of penile cancer. Eur Urol 5:1313-1318 ((discussion 1318-9))

Kim JW, Kim YS, Ko WJ et al (2018) Prognostic factors of penile cancer and the efficacy of adjuvant treatment after penectomy: results from a multi-institution study. J Korean Med Sci 33(37):e233

Kroon BK, Horenblas S, Lont AP, Tanis PJ, Gallee MP, Nieweg OE (2005) Patients with penile carcinoma benefit from immediate resection of clinically occult lymph node metastases. J Urol 173:816-819

Lal P, Halder S, Datta NR (1999) Carcinoma of the penis metastasizing to the dorsal spine. A case report. Urol Int 62:249-251

Langsenlehner T, Mayer R, Quehenberger F (2008) The role of radiation therapy after incomplete resection of penile cancer. Strahlenther Onkol 184:359-363 
Larke NL, Thomas SL, dos Santos SI, Weiss HA (2011) Male circumcision and penile cancer: a systematic review and meta-analysis. Cancer Causes Control 22:1097-1110

Leijte JA, Kerst JM, Bais E, Antonini N, Horenblas S (2007) Neoadjuvant chemotherapy in advanced penile carcinoma. Eur Urol 52:488-494

Leijte JA, Kroon BK, Valdes Olmos RA et al (2007) Reliability and safety of current dynamic sentinel node biopsy for penile carcinoma. Eur Urol 52:170-177

Leijte JA, Kirrander P, Antonini N, Windahl T, Horenblas S (2008) Recurrence patterns of squamous cell carcinoma of the penis: recommendations for follow-up based on a two-centre analysis of 700 patients. Eur Urol 54:161-168

Li F, Xu Y, Wang H et al (2015) Diagnosis and treatment of penile verrucous carcinoma. Oncol Lett 9:1687-1690

Lindner AK, Schachtner G, Steiner E et al (2019) Organ-sparing surgery of penile cancer: higher rate of local recurrence yet no impact on overall survival. World J Urol. https://doi.org/10.1007/ s00345-019-02793-9

Lont AP, Gallee MP, Meinhardt W, van Tinteren H, Horenblas S (2006) Penis conserving treatment for $\mathrm{T} 1$ and $\mathrm{T} 2$ penile carcinoma: clinical implications of a local recurrence. J Urol 176:575-580 ((discussion 580))

Lont AP, Kroon BK, Gallee MP et al (2007) Pelvic lymph node dissection for penile carcinoma: extent of inguinal lymph node involvement as an indicator for pelvic lymph node involvement and survival. J Urol 177:947-952

Lucky M, Murthy KV, Rogers B et al (2015) The treatment of penile carcinoma in situ (CIS) within a UK supra-regional network. BJU Int 115(4):595-598

Mao Y, Hedgire S, Harisinghani M (2014) Radiologic assessment of lymph nodes in oncologic patients. Curr Radiol Rep 2:36

Marban-Orejas MM, Crook J, Keyes M, Dubash R, Batchelar D (2020) High-dose-rate brachytherapy for localized penile cancer: evolution of a technique. Brachytherapy. https://doi.org/10.1016/j. brachy.2019.12.003

McDougal WS (1995) Carcinoma of the penis: improved survival by early regional lymphadenectomy based on the histological grade and depth of invasion of the primary lesion. J Urol 154:1364-1366

Ministério da saúde. Secretaria de vigilância em saúde. Departamento de vigilância das doenças transmissíveis. Coordenação-geral do programa nacional de imunizações. Informe técnico da ampliação da oferta das vacinas papilomavírus humano 6,11,16 e 18 (recombinante) - vacina HPV quadrivalente e meningocócica C (conjugada) [Internet]. Brasília 2018. https://saude.gov.br/image s/pdf/2018/marco/14/Informe-T--cnico-HPV-MENINGITE.pdf. Accessed 9 Mar 2020

Myers JB, Porten SP, McAninch JW (2011) The outcomes of perineal urethrostomy with preservation of the dorsal urethral plate and urethral blood supply. Urology 77:1223-1227

Necchi A, Lo Vullo S, Perrone F et al (2018) First-line therapy with dacomitinib, an orally available pan-HER tyrosine kinase inhibitor, for locally advanced or metastatic penile squamous cell carcinoma: results of an open-label, single-arm, single-centre, phase 2 study. BJU Int 121:348-356

Ng SS, Hutubessy R, Chaiyakunapruk N (2018) Systematic review of cost-effectiveness studies of human papillomavirus (HPV) vaccination: 9-Valent vaccine, gender-neutral and multiple age cohort vaccination. Vaccine 36:2529-2544

Nicholson S, Hall E, Harland SJ et al (2013) Phase II trial of docetaxel, cisplatin and 5FU chemotherapy in locally advanced and metastatic penis cancer (CRUK/09/001). Brit J Cancer 109:2554-2559

O'Kane HF, Pahuja A, Ho KJ, Thwaini A, Nambirajan T, Keane P (2011) Outcome of glansectomy and skin grafting in the management of penile cancer. Adv Urol 2011:240824
Ornellas AA, Kinchin EW, Nobrega BLB, Wisnescky A, Koifman N, Quirino R (2008) Surgical treatment of invasive squamous cell carcinoma of the penis: Brazilian national cancer institute longterm experience. J Surg Oncol 97:487-495

Pagliaro LC, Williams DL, Daliani D et al (2010) Neoadjuvant paclitaxel, ifosfamide, and cisplatin chemotherapy for metastatic penile cancer: a phase II study. J Clin Oncol 28:3851-3857

Paner GP, Stadler WM, Hansel DE et al (2018) Updates in the eight edition of the tumor node metastasis staging classification for Urologic cancers. Eur Urol 73:560

Park JM, Charnsangavej C, Yoshimitsu K, Herron DH, Robinson TJ, Wallace S (1994) Pathways of nodal metastasis from pelvic tumors: CT demonstration. RadioGraphics 14:1309-1321

Pham MN, Deal AM, Ferguson JE 3rd et al (2017) Contemporary survival trends in penile cancer: results from the National Cancer Database. Urol Oncol 35:674.e1-674.e9

Pietrzak P, Corbishley C, Watkin N (2004) Organ-sparing surgery for invasive penile cancer: early follow-up data. BJU Int 94:1253-1257

Pizzocaro G, Piva L, Bandieramonte G, Tana S (1997) Up-to-date management of carcinoma of the penis. Eur Urol 32:5-15

Pizzocaro G, Nicolai N, Milani A (2009) Taxanes in combination with cisplatin and fluorouracil for advanced penile cancer: preliminary results. Eur Urol 55:546-551

Ravi R (1993) Correlation between the extent of nodal involvement and survival following groin dissection for carcinoma of the penis. Br J Urol 72:817-819

Razzaghi H, Saraiya M, Thompson TD, Henley SJ, Viens L, Wilson R (2018) Five-year relative survival for human papillomavirusassociated cancer sites. Cancer 124:203-211

Robinson R, Marconi L, MacPepple E et al (2018) Risks and benefits of adjuvant radiotherapy after inguinal lymphadenectomy in node-positive penile cancer: a systematic review by the European Association of Urology Penile Cancer Guidelines Panel. Eur Urol 74(1):76-83

Rouscoff Y, Falk AT, Durand M et al (2014) High-dose rate brachytherapy in localized penile cancer: short-term clinical outcome analysis. Radiat Oncol 9:142

Saad F, Gleason DM, Murray R et al (2004) Long-term efficacy of zoledronic acid for the prevention of skeletal complications in patients with metastatic hormone-refractory prostate cancer. J Natl Cancer Inst 96:879-882

Sharma P, Djajadiningrat R, Zargar-Shoshtari K et al (2015) Adjuvant chemotherapy is associated with improved overall survival in pelvic node-positive penile cancer after lymph node dissection: a multi-institutional study. Urol Oncol 33:496.e17

Shylasree TS, Bryant A, Howells RE (2011) Chemoradiation for advanced primary vulval cancer. Cochrane Database Syst Rev. 13(4):CD003752

Skeppner E, Andersson SO, Johansson JE, Windahl T (2012) Initial symptoms and delay in patients with penile carcinoma. Scand $\mathrm{J}$ Urol Nephrol 46:319-325

Slaton JW, Morgenstern N, Levy DA et al (2001) Tumor stage, vascular invasion and the percentage of poorly differentiated cancer: independent prognosticators for inguinal lymph node metastasis in penile squamous cancer. J Urol 165:1138-1142

Spiess PE, Izawa JI, Bassett R et al (2007) Preoperative lymphoscintigraphy and dynamic sentinel node biopsy for staging penile cancer: results with pathological correlation. J Urol 177:2157-2161

Tang DH, Djajadiningrat R, Diorio G et al (2017) Adjuvant pelvic radiation is associated with improved survival and decreased disease recurrence in pelvic node-positive penile cancer after lymph node dissection: a multi-institutional study. Urol Oncol 35:605.e17-605.e23

Theodore C, Skoneczna I, Bodrogi I et al (2008) A phase II multicentre study of irinotecan (CPT 11) in combination with cisplatin 
(CDDP) in metastatic or locally advanced penile carcinoma (EORTC PROTOCOL 30992). Ann Oncol 19:1304-1307

Tsaur I, Biegel C, Gust K et al (2015) Feasibility, complications and oncologic results of a limited inguinal lymph node dissection in the management of penile cancer. Int Braz J Urol 41:486-495

Veeratterapillay R, Teo L, Asterling S, Greene D (2015) Oncologic outcomes of penile cancer treatment at a UK supraregional center. Urol 85:1097-1103

Velazquez EF, Ayala G, Liu H et al (2008) Histologic grade and perineural invasion are more important than tumor thickness as predictor of nodal metastasis in penile squamous cell carcinoma invading 5 to $10 \mathrm{~mm}$. Am J Surg Pathol 32:974-979

Viani G, Hamamura AC, Faustino AC (2019) Intensity modulated radiotherapy (IMRT) or conformational radiotherapy (3D-CRT) with conventional fractionation for prostate cancer: Is there any clinical difference? Int Braz J Urol 45(6):1105-1112

Winters BR, Kearns JT, Holt SK, Mossanen M, Lin DW, Wright JL (2018) Is there a benefit to adjuvant radiation in stage III penile cancer after lymph node dissection? Findings from the National Cancer Database. Urol Oncol 36:92.e11-92.e16

Xu J, Li G, Zhu SM et al (2019) Neoadjuvant docetaxel, cisplatin and ifosfamide (ITP) combination chemotherapy for treating penile squamous cell carcinoma patients with terminal lymph node metastasis. BMC Cancer 19:625

Yamashita T, Ogawa A (1989) Ultrasound in penile cancer. Urol Radiol 11:174-177
Yuan T, Fitzpatrick T, Ko NY et al (2019) Circumcision to prevent HIV and other sexually transmitted infections in men who have sex with men: a systematic review and meta-analysis of global data. Lancet Glob Health 7:e436-e447

Zargar-Shoshtari K, Djajadiningrat R, Sharma P et al (2015) Establishing criteria for bilateral pelvic lymph node dissection in the management of penile cancer: lessons learned from an international multicenter collaboration. J Urol 194:696-701

Zargar-Shoshtari K, Sharma P, Djajadiningrat R et al (2016) Extent of pelvic lymph node dissection in penile cancer may impact survival. World J Urol 34:353-359

Zhu Y, Zhou XY, Yao XD, Dai B, Ye DW (2007) The prognostic significance of p53, Ki-67, epithelial cadherin and matrix metalloproteinase-9 in penile squamous cell carcinoma treated with surgery. BJU Int 100:204-208

Zhu Y, Zhang SL, Ye DW, Yao XD, Jiang ZX, Zhou XY (2008) Predicting pelvic lymph node metastases in penile cancer patients: a comparison of computed tomography, Cloquet's node, and disease burden of inguinal lymph nodes. Onkol 31:37-41

Zouhair A, Coucke PA, Jeanneret W et al (2001) Radiation therapy alone or combined surgery and radiation therapy in squamouscell carcinoma of the penis? Eur J Cancer 37:198-203

Publisher's Note Springer Nature remains neutral with regard to jurisdictional claims in published maps and institutional affiliations.

\section{Affiliations}

\section{Andrey Soares ${ }^{1,2,3}$ (D) Icaro Thiago de Carvalho $0^{4,5}$ - Aluízio Gonçalves da Fonseca ${ }^{6}$. \\ Antonio Machado Alencar Jr. ${ }^{7,8}$. Carlos Heli Bezerra Leite ${ }^{9}$. Diogo Assed Bastos ${ }^{3,10}$. João Paulo Holanda Soares ${ }^{11}$. Katia Ramos Moreira Leite ${ }^{12}$ (1) - Mário Ronalsa Brandão Filho ${ }^{13} \cdot$ Ronald Wagner Pereira Coelho ${ }^{3,14}$. Sandro Roberto de A. Cavallero ${ }^{3,15,16}$. Stênio de Cassio Zequi ${ }^{17,18}$. José de Ribamar Rodrigues Calixto ${ }^{19}$}

1 Department of Oncology, Centro Paulista de OncologiaOncoclínicas, Av. Brigadeiro Faria Lima, 4300, Vila Olímpia, São Paulo, SP 01452-000, Brazil

2 Department of Oncology, Hospital Israelita Albert Einstein, Av. Albert Einstein, 627, Morumbi, São Paulo, SP 05652-900, Brazil

3 Latin American Cooperative Oncology Group, Porto Alegre, Rio Grande do Sul, Brazil

4 Department of Radiotherapy, Hospital Israelita Albert Einstein, São Paulo, São Paulo, Brazil

5 Instituto Abathon, São Paulo, São Paulo, Brazil

6 Department of Urology, Hospital Ophir Loyola, Belém, Pará, Brazil

7 Department of Oncology, Hospital Universitário da Universidade Federal do Maranhão, São Luís, Maranhão, Brazil

8 Department of Oncology, Hospital São Domingos, São Luís, Maranhão, Brazil

9 Department of Radiotherapy, Hospital Haroldo Juaçaba, Fortaleza, Ceará, Brazil

10 Department of Oncology, Hospital Sírio-Libanês, São Paulo, São Paulo, Brazi
11 Department of Oncology, Hospital Haroldo Juaçaba, Fortaleza, Ceará, Brazil

12 Medical Research Laboratory of the Discipline of Urology, Faculdade de Medicina da USP, São Paulo, São Paulo, Brazil

13 Department of Urology, Santa Casa de Misericórdia de Maceió, Maceió, Alagoas, Brazil

14 Department of Oncology, Hospital do Câncer Aldenora Bello, São Luís, Maranhão, Brazil

15 Department of Oncology, Hospital Adventista de Belém, Belém, Pará, Brazil

16 Department of Oncology, Centro de Tratamento Do Pará, Belém, Pará, Brazil

17 Department of Urology, AC Camargo Cancer Center, São Paulo, São Paulo, Brazil

18 National Institute for Science and Technology in Oncogenomics and Therapeutic Innovation, AC Camargo Cancer Center, São Paulo, São Paulo, Brazil

19 Department of Urology, Hospital Universitário Presidente Dutra, UFMA, São Luís, Maranhão, Brazil 